\title{
Pollen morphological analysis of the genus Lallemantia (Lamiaceae) of Iran
}

\author{
Fahimeh Koohdar ${ }^{1}$, Masoud Sheidai ${ }^{1}$, Zeynab Moradian Poode ${ }^{1}$, Seyed Mehdi Talebi ${ }^{2 \star}$ \\ ${ }^{1}$ Faculty of Life Sciences and Biotechnology, Shahid Beheshti University, Tehran, Iran; \\ Email:f_koohdar@yahoo.com,msheidai@yahoo.com,zeinab93mrd@gmail.com \\ 2 Department of Boilogy, Faculty of Science, Arak University, Arak, Iran. \\ Email:seyedmehdi_talebi@yahoo.com \\ Author for correspondence: seyedmehdi_talebi@yahoo.com
}

\begin{abstract}
Lallemantia is a small genus of Lamiaceae with five herbaceous annual or biennial species. Some of these species are of medicinal value, while others have been used as the source of food. All five Lallemantia species occur in Iran. Although, there are many discussions about infra-generic variations in the genus, very scarce comprehensive studies are found about its taxonomy. Therefore, in the current study, pollen grain morphology was investigated using scanning electron microscopy. We used SPSS ver. 15 and PAST ver. 2.17 for multivariate statistical analyses of data. In total, we studied eleven qualitative and quantitative traits. Pollen equatorial and polar views were similar among the species and were prolate and circular, respectively. Pollen ornamentations differed as bireticulate (L. royleana and L. iberica), microreticulatm (L. peltata and L. Baldshuanica) and reticulate- faveolate (L. canescens). PCA-biplot showed some traits such as pori length/width ratio were important in identifications of species. The studied species created two groups in the WARD method tree of palynological data. L. royleana and L. baldshuanica were grouped together, and in the other group L. canescens and L. iberica placed nearly and L. peltata placed far from them. Our obtained results were similar to previous morphological study of the genus. The present study revealed taxonomic implication of the micromorphological study in the interspecific classification of the genus.
\end{abstract}

Key words: Lallemantia, Pollen, taxonomy, species relationship.

\section{Introduction}

Lallemantia Fisch. \& C. A. Mey. is a genus of subfamily Nepetoideae, tribe Mentheae of family Lamiaceae. It is a small genus with 5 species that are herbaceous annual or biennial plants. These species characterized by simple leaves; a thyrsoid, spike-like or oblong, often interrupted inflorescence; ovate to rotund or sometimes linear, aristate-toothed bracteoles; and oblong, trigonous, smooth and mucilaginous nutlets (Harley et al., 2004).

Lallemantia species are widely distributed in different parts of the world such as Afghanistan, China, India, Kazakhstan, Kyrgyzstan, Pakistan, Iran, Russia, Tajikistan, Turkmenistan, Uzbekistan, SW Asia and Europe, with the Caucasian region as the center of its origin. All five Lallemantia species occur in Iran (Rechinger, 1982).

Some of Lallemantia species are of medicinal value (Mahmood et al., 2013), while others have been used as the source of food (Rivera Nunez, 1992). For example, Lallemantia royleana (Benth. in Wall.) Benth., is commonly called as Balangu, Tukhm-e-balanga or Balangu-e-shirazi, is an important medicinal plant in Iranian folk medicine. In addition, this aromatic herb is cultivated in various parts of the world such as North India for the sake of its highly medicinal and mucilaginous seeds that are widely used as remedial agents in different disorders. Different studies (Naghibi et al., 2005; Razavi, Karazhiyan, 2009; Razavi, Moghaddam, 2011) showed that nutlets of these plants are more common part of traditional medicine, although there are very limited data about its nutritive components. It seems that seed contains carbohydrates, oil, fiber, tannins and protein. 
Several studies have been conducted using light microscopy and scanning electron microscopy in order to describe pollen grain features and to examine the available classification of Lamiaceae family (Abu-Asab, Cantino, 1994; OybakDönmez et al., 1999; Dinç, Öztürk, 2008).

Kamrani and Riahi (2017), examined phylogenetic relationships among the Lallemantia species and its close allies (Lamiaceae, Mentheae) using nuclear (ITS) and plastid (trnL, $t r n \mathrm{~L} / \mathrm{F}$, $t r n S / G, r p B 2$, and $r p / 32-t r n \mathrm{~L}$ ) DNA sequences. Their findings from bayesian and parsimony analyses proved that Lallemantia is monophyletic.

Erdtman (1945) based on different palynological variables, such as aperture number and number of nuclei in shed pollen, divided the Lamiaceae family into two main subfamilies: Lamioideae and Nepetoideae. In Lallemantia the pollen grains are generally symmetrical, isopolar, zonohexacolpate and prolate to prolate-spheroidal in shape (Dinç et al., 2009).

Very scares studies are found about the infrageneric classification of the genus in the world and most of them were not comprehensive. Because, all five species of the genus are only found in Iran and in the other countries we have up to three species. For example, Dinç et al. (2009) could differentiate three species, namely Lallemantia iberica, L. canescens, and L. peltata occurring in Turkey by using micro-morphological features related to the pollen, nutlet and trichome.

At yet, we have no report on pollen grain morphology of the genus in Iran. Therefore the aims of the present study are to describe pollen grains characters in five species of Lallemantia and evaluate the taxonomic importance of palynological data as well as species relationship in this genus. Furthermore, pollen morphological traits of L. royleana and L. baldshuanica Gontsch. were described by the first time for the world.

\section{Material and methods}

Plant materials

Extensive field visits and collections were undertaken during 2014-2015. We selected one population of each species, and per each population five flowering stems (in total 25 plant specimens) were randomly collected and used for pollen grain morphological studies. The plant samples were identified based on the descriptions provided in Flora Iranica (Rechinger, 1982) and Flora of Iran (Jamzad, 2012).The voucher specimens are deposited in the herbarium of Shahid Beheshti University (HSBU) (Table1 and Fig.1).

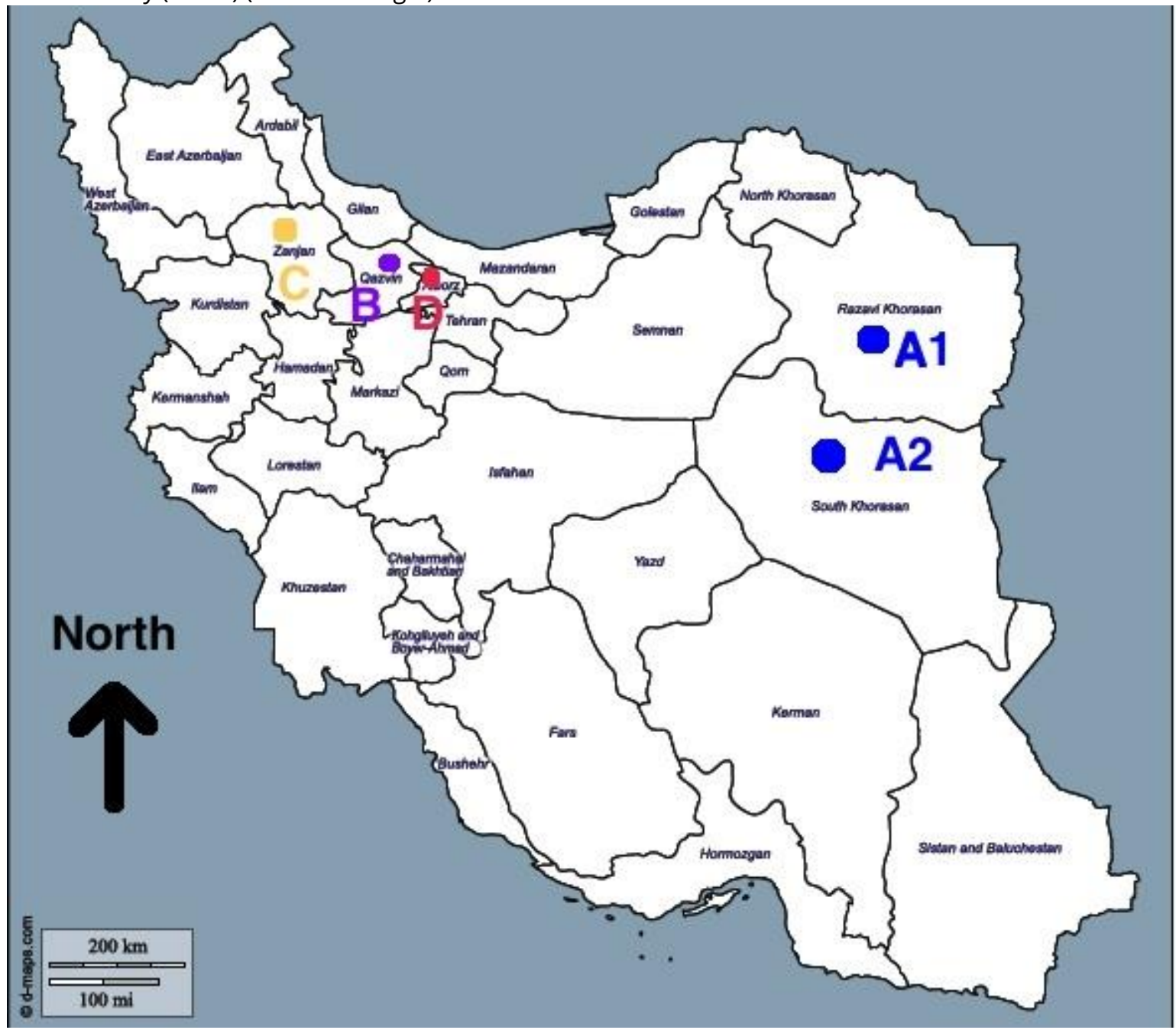


Fig. 1. Distribution map of studied populations of Lallemantia species $(A 1=L$. baldshuanica, $A 2=L$. royleana, $B=L$. canescens, $\mathrm{C}=$ L. iberica, and $\mathrm{D}=$ L. peltata).

In total, we examined eleven qualitative and quantitative palynological variables. The studied palynological features were: polar and equatorial axes view, exine ornamentation type, polar axis length (P), equatorial axis length (E), polar / equatorial (P/E) length ratio, mesocolpium length (LC), pori length, pori width, apocolpium length and width.

Table1. Lallemantia species studied, their localities and voucher numbers

\begin{tabular}{llll}
\hline & Species & Locality & Voucher number \\
1 & L. peltata (L.) Fisch. \& C. A. Mey. & Albourz province, Chalous road, 1950 m. & HSBU 201209 \\
2 & L. canescens(L.) Fisch. \& C. A. Mey. & Qazvin province, Alamout, 2500 m. & HSBU 201200 \\
3 & L. baldshuanica Gontsch. & Khorasan Razavi province, Mashhad, Kalat, 1200 m. & HSBU 201208 \\
4 & L. iberica(Stev.)Fisch. \& C. A. Mey. & Zanjan province, before Abhar, 1700 m. & HSBU 201210 \\
5 & L. royleana (Benth. in Wall.)Benth. & South Khorasan province,1200 m. & HSBU 201212 \\
\hline
\end{tabular}

\section{Samples preparation}

For SEM micrographs, pollen grain samples mounted on the stubs using double-sided adhesive tape and coated with gold in spotter coater. The specimens were examined and photographed using a Phillips $\times$ L20 Scanning Electron Microscopy. From each species twenty intact pollen grains were selected. UTHSCSA Image Tool Version 3.0 was used to carry out required measurements.

Statistical descriptions of the quantitative and qualitative palynological features of Lallemantia species growing in Iran are given in Table 2. Pollen terminology follows Faegri and Iversen (1989) and Punt et al. (1994).

Table 2. Details of pollen morphology in Lallemantia species (all values are in $\mu \mathrm{m}$ ).

\begin{tabular}{|c|c|c|c|c|c|}
\hline Characters & $\begin{array}{l}\text { L. } \\
\text { baldshuanica }\end{array}$ & L. iberica & L. canescens & L. peltata & L. royleana \\
\hline equatorial view & prolate & prolate & prolate & prolate & prolate \\
\hline polar view & circular & circular & circular & circular & circular \\
\hline ornamentation & microreticulate & bireticulate & $\begin{array}{l}\text { reticulate- } \\
\text { faveolate }\end{array}$ & microreticulate & bireticulate \\
\hline Polar axis length $(\mathrm{P})$ & 25.63 & 38.95 & 40.39 & 34.56 & 33.54 \\
\hline Equatorial axis length (E) & 17.4 & 24.2 & 28.36 & 18.24 & 23.73 \\
\hline \multicolumn{6}{|l|}{ Polar/equatorial length ratio } \\
\hline$(P / E)$ & 1.47 & 1.60 & 1.42 & 1.30 & 1.41 \\
\hline Mesocolpium length (LC) & 7.23 & 9.39 & 9.54 & 7.42 & 7.87 \\
\hline Pori Length & 0.34 & 0.54 & 0.61 & 0.47 & 0.35 \\
\hline Pori Width & 0.2 & 0.31 & 0.39 & 0.3 & 0.23 \\
\hline Apocolpium length & 1.35 & 1.45 & 1.54 & 1.5 & 1.33 \\
\hline Apocolpium width & 0.7 & 1.27 & 1.5 & 1.8 & 0.92 \\
\hline
\end{tabular}

\section{Data analyses}

The quantitative palynological variables were first standardized (Mean $=0$, Variance $=1$ ) and used to the establish Euclidean distance among pairs of species. For grouping of the plant species, the WARD (Minimum spherical characters) tree with PAST program was used. PCA (Principal components analysis) biplot was used to identify the most variable characters among the studied species (Podani, 2000). PAST version 2.17 and SPSS ver. 15 (Hammer et al. 2012) were used for statistical analyses of data.

\section{Results}

The pollen grains in all studied species were monad, isopolar, symmetrical, zonohexacolpate and prolate in shape. Selected electron micrographs of pollen grains were presented in Fig. 2.

The polar and equatorial views were similar in all species and were circular and prolate, respectively. However, the pollen ornamentations differed among the species and were observed as bireticulate ( $L$. royleana and $L$. iberica), microreticulate ( $L$. peltata and L. baldschuanica) and reticulate- faveolate ( $L$. canescens).

We registered the highest polar $(P)$ and equatorial axes length $(E)$ in $L$. canescens (40.39 and $28.36 \mu \mathrm{m}$, respectively), while $L$. baldshuanica had the smallest polar and equatorial axes length ( 25.63 and17.4 $\mu$ m, respectively). Similarly, we founded the highest sizes of pori length $(0.61 \mu \mathrm{m})$ and width $(0.39 \mu \mathrm{m})$ in $L$. canescens, and the smallest pori length $(0.34$ $\mu \mathrm{m})$ and width $(0.2 \mu \mathrm{m})$ in L. baldshuanica. 
Significant positive correlations were found between some quantitative palynological variables. For example, polar axis length had a significant positive correlation $(p \leq 0.05)$ with pori length $(r=0.88)$ and pori width $(r=0.89)$. A significant positive correlation ( $p \leq 0.05, r=0.88$ ) was recorded between mesocolpium length with equatorial axis length. Apocolpium length significantly correlated $(p \leq 0.05, r=0.88)$ with apocolpium width.

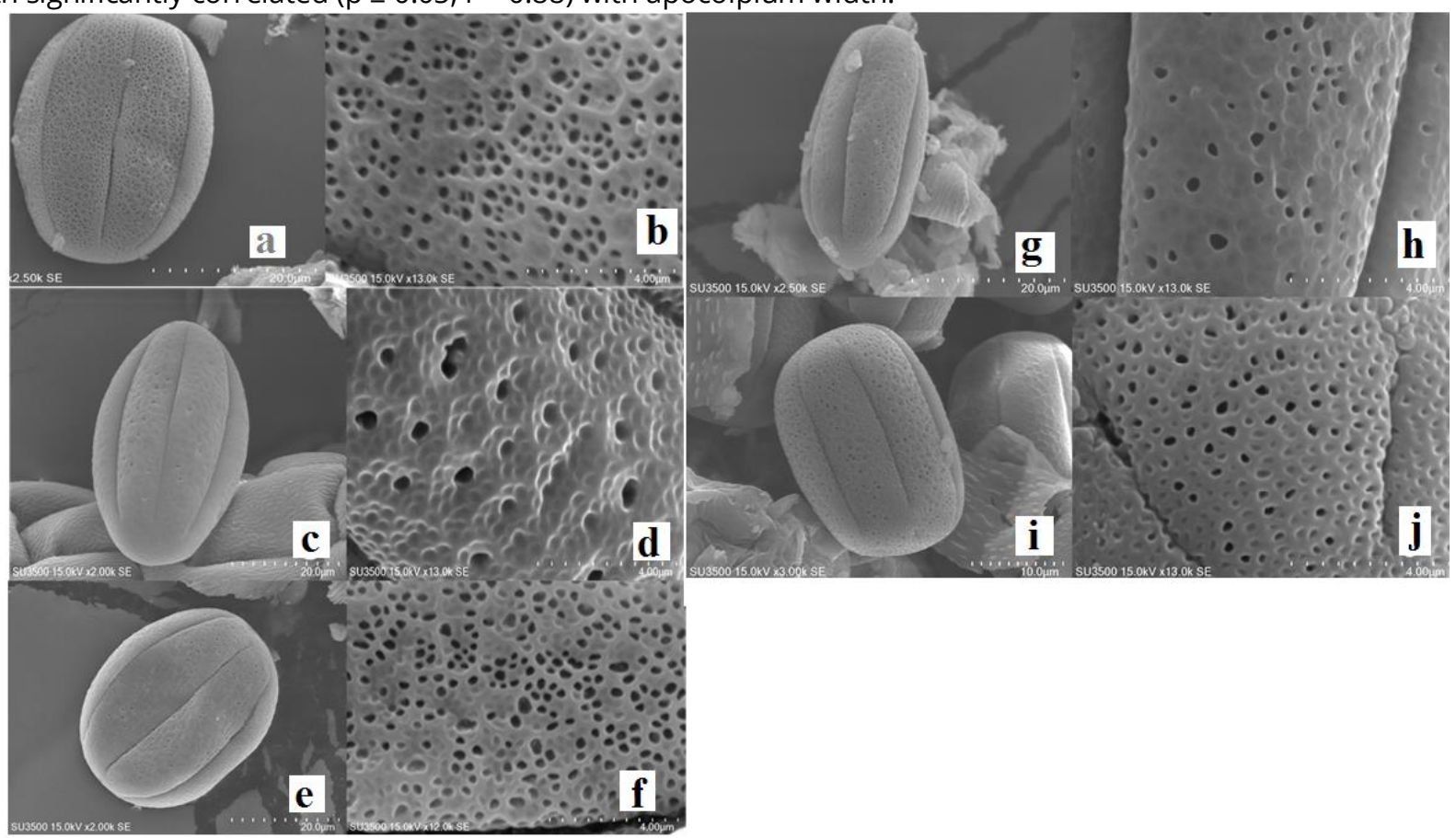

Fig. 2. Electron micrographs of pollen grain equatorial view (left) and exine surface ornamentation (right): (a, b) $L$. royleana, $(\mathrm{c}, \mathrm{d})$ L. canescens, $(\mathrm{e}, \mathrm{f})$ L. iberica, $(\mathrm{g}, \mathrm{h})$ L. peltata, $(\mathrm{i}, \mathrm{j})$ L. baldshuanica.

PCA-biplot showe that some palynological variables such as pori length/width ratio had taxonomic value and was useful in identification of Lallemantia species. The studied populations were separated in the WARD dendrogram of palynological data and placed in two groups. In smaller one, L. royleana and L. baldshuanica were seen and the rest species were the biggest group, so L. iberica and L. canescens were closer and L. peltata place far from them( Fig 3). Distance
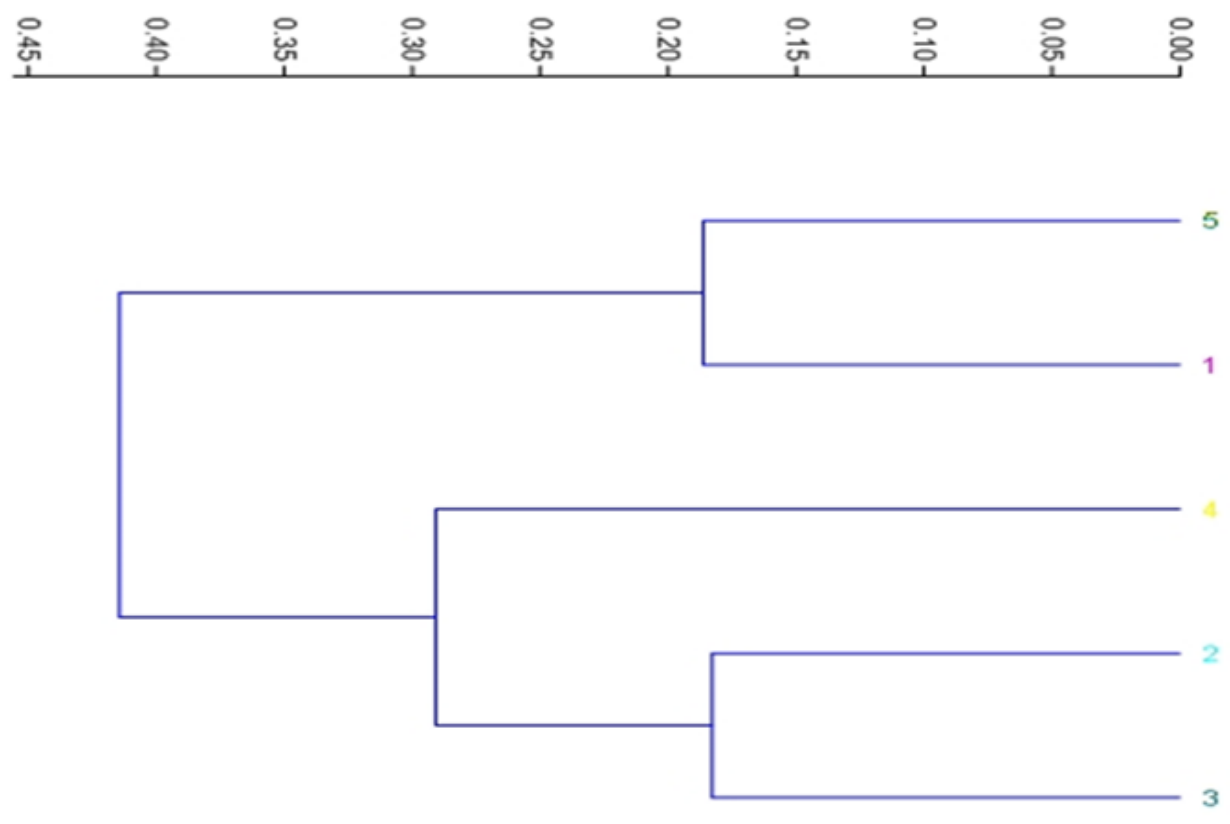

Fig. 3. WARD dendrogram of the studied Lallemantia species based on the pollen morphology. 1: L. royleana, 2: L. canescens, 3: L. iberica, 4: L. peltata, 5. L. baldschuanica. 


\section{Discussion}

In the current study, we investigated pollen morphological variables in five species of Lallemantia. There are many discussions about infra-generic classifications of the genus and different synonyms were definite for its species (Rechinger, 1982). Moreover, the highest morphological similarities exist among this species, so identifications of some species are very difficult. Therefore, we decide to use other taxonomic tools such as pollen morphological traits for improvement of infra-generic classification of this problematic genus.

Palynology is one of strong taxonomic tools that were useful in taxonomic treatments for various families such as Linaceae (Talebi et al., 2012), Amaranthaceae (Talebi et al., 2016). Moreover, palynological study has been shown a wide range of variations and has diagnostic value of species recognition and taxonomy of Lamiaceae (Navarro, El Oualidi, 2000; Jurišić Grubešić et al., 2007; Dinç, Öztürk, 2008). For example, Tabaripour et al. (2018) used palynological features for improvement of infraspecific classification of Ziziphora capitata.

We observed that polar and equatorial shapes were stable among the studied species. Our find were agreed with DINÇ et al. (2009). They registered circular and more or less prolate as the polar and equatorial views for $L$. canescens, $L$. iberica and L. peltata. It seems that these traits have no taxonomic importance of Lallemantia species. Beside, several studies (Moon and Hong, 2006; Kaya and Kutluk, 2007; Moon et al., 2008a, b) have proved that variations in polar and equatorial shapes have very limited and no taxonomic importance in Labiatae family.

Pollen equatorial and polar axes length differed among the studied species. We compared the size of pollen grains in our studied species with similar study on these species and founded that the size of pollen grains is a semi-plastic trait. Therefore, it cannot be used as a good trait for species identification. For example, pollen equatorial axis length is given for L. peltata, L. iberica and L. canescens by Dinç et al. (2009) as 22.00, 23.30 and $29.30 \mu$ m, respectively, while we recorded as 18.24, 24.20 and $28.36 \mu \mathrm{m}$, respectively. Therefore, infraspecific variations occur in pollen size and environmental factors or genetic impress pollen size.

Pollen aperture type was similar among the studied species and also were alike with those were reported by Dinç et al. (2009) .We registered three types of pollen exine ornamentations among the species and it seems that it is a good characteristic for identification of species, especially L. royleana from L. baldshuanica, which are morphologically very similar. We compared our observed exine ornamentations with those were reported by Dinç et al. (2009) and founded our results were in agreement with their study except for one species ( $L$. iberica).

Although, some degree of infraspecific differences was recorded for exine ornamentations, Brochmann (1992) has been stated that the pollen exine ornamentation is a good trait for ascertaining relationships among species, and in Lamiaceae its usefulness in infrageneric and even interspecific classification is proved in various studies (Kaya, Kutluk, 2007; Moon et al., 2008a, b; Akgül et al., 2008; Dinç, Öztürk, 2008).

In WARD tree of palynological data, L. royleana and L. baldshuanica placed close together. These species are morphologically very similar and identification of them is very difficult. Based on morphological studies, Talebi (2006) considered $L$. royleana and $L$. baldshuanica close to each other as they share very similar features. $L$. iberica and $L$. canescens grouped closely and L. peltata were joined them. Our findings were similar to more recent phylogenetic study of the genus. In a phylogenetic study of Kamrani and Riahi (2017) two monophyletic groups were identified. One including $L$. royleana and $L$. baldshuanica, and the other consisting of $L$. canescens and $L$. iberica that is sister to $L$. peltata with the support of $100 \%$ BP and 1.00 PP

Dinç et al. (2009) also considered L. iberica and L. peltata close to each other, while, L. canescens was placed far from due to pollen morphology. On the other hand, our findings for these species were not in agreement with Dinç et al. (2009) study.

\section{References}

Abu-Assab, M.S., Cantino, P.D. (1994). Systematic implications of pollen morphology in subfamilies Lamioideae and Pogostemonoideae (Labiatae). Annals of the Missouri Botanical Garden, 81, 653-686.

Brochmann, C. (1992). Pollen and seed morphology of Nordic Draba (Brassicaceae): phylogenetic and ecological implications. Nordic Journal of Botany, 1, 657-673.

Dinç, M., Öztürk, M. (2008). Comparative morphological, anatomical and palynological studies on the genus Stachys L. sect. Ambleia Bentham (Lamiaceae) species in Turkey. Turkish Journal of Botany, 32, 113-121.

Dinç, M., Pinar, N., Dogu, S., Yildirimli, S. (2009). Micromorphological studies of Lallemantia L. (Lamiaceae) species growing in Turkey. Acta Biologica Cracoviensia Series Botanica, 51, $45-54$.

Erdtman, G. (1945). Pollen morphology and plant taxonomy, IV. Labiatae, Verbenaceae, and Aviceniaceae. Svensk Botanisk Tidskrft, 39, 279- 285.

Harley, R.M., Atkins, S., Budantsev, A.L., Cantino, P.D., Conn, B.J., Grayer, R., Harley, M.M., De Kok, R., Krestovskaja, T., Morales, R., Paton, A.J., Ryding, O., Upson, T. (2004). The families and genera of vascular plants. In: Kadereit, J.W. (Ed.), Lamiaceae (Lamiales). Springer, Berlin, pp. 167-282.

Hammer, O., Harper, D.A., Ryan, P.D. (2012). PAST: Paleontological Statistics software package for education and data analysis. Paleontologia Electronica, 4, 9.

Jamzad, Z. (2012). Flora of Iran, no. 76, Lamiaceae. Research Institute of Forest and Rangelands, Tehran, Iran. 
Jurišić Grubešić, R., Vladimir-Knežević, S., Kremer, D., Kalodera, Z., Vuković, J. (2007). Trichome micromorphology in Teucrium (Lamiaceae) species growing in Croatia. Biologia (Bratislava), 62, 148-156.

Kamrani, A., Riahi, M. (2017). Using molecular data to test the monophyly of Lallemantia in the subtribe Nepetinae (Mentheae, Lamiaceae), Plant Biosystems - An International Journal Dealing with all Aspects of Plant Biology, DOI: 10.1080 /11263504.2017.1359210

Kaya, A., Kutluk, H. (2007). Pollen morphology of Acinos Miller species growing in Turkey. Journal of Integrative Plant Biology, 49. 1386-1392.

Moon, H.K., Hong, S.P. (2006). Nutlet morphology and anatomy of the genus Lycopus (Lamiaceae: Mentheae). Journal of Plant Research, 119. 633-644.

Mahmood, S., Hayat, M.Q., Sadiq, A., Ishtiaq, S.H., Malik, S., Ashraf, M. (2013). Antibacterial activity of Lallemantia royleana (Benth.) indigenous to Pakistan. African Journal of Microbiology Research, 7 (31), 4006-4009

Moon, H.K., Smets, E., Walker, J.B., Smets, E., Huysmans, S. (2008a). A search for phylogenetically informative pollencharacters in the subtribe Salviinae (Mentheae: Lamiaceae). International Journal of Plant, 169, 455-471.

Moon, H.K., Vinckier, S., Smets, E., Huysmans, S. (2008b). Comparative pollen morphology and ultrastructure of Mentheae subtribe Nepetinae (Lamiaceae). Review of Palaeobotany and Palynology, 149, 174-186.

Naghibi, F., Mosaddegh, M., Motamed, S.M., Ghorbani, A. (2005). Labiatae family in folk medicine in Iran: from ethnobotany to pharmacology. Iranian Journal of Pharmaceutical Research, 2, 63-79.

Navarro T., El Oualidi, J. (2000). Trichome morphology in Teucrium L. (Lamiaceae). A taxonomic review. Annals of the Botanical Garden of Madrid, 57, 277-297.

Oybak-Dönmez, E., Inceoglu, Ö., Pinar, N.M. (1999). Scanning electron microscopy study of pollen in Some Turkish Teucrium L. (Lamiaceae). Turkish Journal of Botany, 23, 379-382.

Podani, J. (2000). Introduction to the Exploration of Multivariate Data. Backhuyes, Leiden.

Razavi, S.M.A., Karazhiyan, H. (2009). Flow properties and thixotropy of selected hydrocolloids, Experimental and modeling studies. Food Hydrocolloids, 23(3), 908-912.

Razavi, S.M.A., Moghaddam, T.M. (2011). Influence of different substitution levels of Lallemantia royleana seed gum on textural characteristics of selected hydrocolloids. Electronic Journal of Environmental, Agricultural and Food Chemistry, 10, 2826-2837.

Rechinger, K.H. (1982). Lallemantia. In: Flora Iranica, 150. Akademische Drucku. Verlagsanstalt, Graz, Austria.

Rivera Nunez, D., Obon, D.E., Gastro, C. (1992). The ethnobotany of Lamiaceae of old world. In: Harley R.M., Reynolds T. (ED.) Advances in Lamiaceae Science. Royal Botanical Gardens, Kew, 455-473.

Tabaripour, R., Sheidai, M., Talebi, S.M., Noormohammadi, Z. (2018). Genetic divergence and speciation within Ziziphora capitate (Lamiaceae): Molecular and micromorphological evidences. Biodiversitas, 19, 667-675.

Talebi, S.M. (2006). Morphology, anatomy and chemotaxonomy of the genus Lallemantia in Iran. Thesis of Doctoral Dissertation. Shahid Beheshti University, Iran (in Persian).

Talebi, S.M., Noori, M., Nasiri, Z. (2016). Palynological study of some Iranian Amaranthus taxa. Environmental and Experimental Biology, 14, 1-7.

Talebi, S.M., Sheidai, M., Atri, M., Sharifnia, F., Noormohammadi Z. (2012). Palynological study of the genus Linum in Iran (a taxonomic review). Phytologia Balcanica, 18, 293-303.

\section{Citation:}

Koohdar, F., Sheidai, M., Poode, Z.M., Se Talebi, S.M. (2018). Pollen morphological analysis of the genus Lallemantia (Lamiaceae) of Iran. Acta Biologica Sibirica, 4 (3), 115-120.

Submitted: 21.06.2018. Accepted: 13.08.2018

cross $^{\text {ref }}$ http://dx.doi.org/10.14258/abs.v4i3.4416

(C) 2018 by the authors. Submitted for possible open access publication under the terms and conditions of the Creative Commons Attribution (CC BY) license (http://creativecommons.org/licenses/by/4.0/). 